\title{
Both SEPT2 and MLL are down-regulated in MLL-SEPT2 therapy-related myeloid neoplasia
}

Nuno Cerveira ${ }^{1}$, Joana Santos ${ }^{1}$, Susana Bizarro ${ }^{1}$, Vera Costa ${ }^{1}$, Franclim R Ribeiro ${ }^{1}$, Susana Lisboa ${ }^{1}$, Cecília Correia ${ }^{1}$, Lurdes Torres ${ }^{1}$, Joana Vieira ${ }^{1}$, Simone Snijder ${ }^{2}$, José M Mariz ${ }^{3}$, Lucília Norton ${ }^{4}$, Clemens H Mellink ${ }^{2}$, Arjan Buijs ${ }^{5}$ and Manuel R Teixeira*1,6

\begin{abstract}
Address: ${ }^{1}$ Department of Genetics, Portuguese Oncology Institute, Porto, Portugal, ${ }^{2}$ Department of Clinical Genetics, Academic Medical Center, Amsterdam, The Netherlands, ${ }^{3}$ Department of Hemato-Oncology, Portuguese Oncology Institute, Porto, Portugal, ${ }^{4}$ Department of Pediatrics, Portuguese Oncology Institute, Porto, Portugal, ${ }^{5}$ Department of Medical Genetics, University Medical Center, Utrecht, The Netherlands and ${ }^{6} \mathrm{Abel}$ Salazar Biomedical Sciences Institute (ICBAS), Porto, Portugal

Email: Nuno Cerveira - nscerveira@gmail.com; Joana Santos - joana.cris.santos@gmail.com; Susana Bizarro - susanabizarro@gmail.com; Vera Costa - veralmcosta@gmail.com; Franclim R Ribeiro - ribeirofr@gmail.com; Susana Lisboa - susanalisboa@hotmail.com; Cecília Correia - correia.cecilia@gmail.com; Lurdes Torres - lurdes_torres@hotmail.com; Joana Vieira - joana_vieira@netcabo.pt; Simone Snijder - s.snijder@amc.uva.nl; José M Mariz - mariz@ipoporto.min-saude.pt; Lucília Norton - lucilia.norton@ipoporto.min-saude.pt; Clemens H Mellink - c.h.mellink@amc.uva.nl; Arjan Buijs - a.buijs@umcutrecht.nl; Manuel R Teixeira* - manuel.teixeira@ipoporto.minsaude.pt

* Corresponding author
\end{abstract}

Published: 15 May 2009

BMC Cancer 2009, 9:147 doi:10.1186/147|-2407-9-147

This article is available from: http://www.biomedcentral.com/I47/-2407/9//47

(C) 2009 Cerveira et al; licensee BioMed Central Ltd.

This is an Open Access article distributed under the terms of the Creative Commons Attribution License (http://creativecommons.org/licenses/by/2.0), which permits unrestricted use, distribution, and reproduction in any medium, provided the original work is properly cited.

\begin{abstract}
Background: A relevant role of septins in leukemogenesis has been uncovered by their involvement as fusion partners in MLL-related leukemia. Recently, we have established the MLL-SEPT2 gene fusion as the molecular abnormality subjacent to the translocation $\mathrm{t}(2 ; 1 \mathrm{I})(\mathrm{q} 37 ; \mathrm{q} 23)$ in therapy-related acute myeloid leukemia. In this work we quantified MLL and SEPT2 gene expression in 58 acute myeloid leukemia patients selected to represent the major AML genetic subgroups, as well as in all three cases of MLL-SEPT2-associated myeloid neoplasms so far described in the literature.
\end{abstract}

Methods: Cytogenetics, fluorescence in situ hybridization (FISH) and molecular studies (RT-PCR, qRT-PCR and qMSP) were used to characterize 58 acute myeloid leukemia patients (AML) at diagnosis selected to represent the major AML genetic subgroups: CBFB-MYHII $(\mathrm{n}=13)$, PML-RARA $(\mathrm{n}=12)$; RUNXI-RUNXITI $(\mathrm{n}=\mid 2)$, normal karyotype $(n=1 \mathrm{I})$, and MLL gene fusions other than MLL-SEPT2 $(\mathrm{n}=10)$. We also studied all three MLL-SEPT2 myeloid neoplasia cases reported in the literature, namely two AML patients and a t-MDS patient.

Results: When compared with normal controls, we found a 12.8-fold reduction of wild-type SEPT2 and MLLSEPT2 combined expression in cases with the MLL-SEPT2 gene fusion $(p=0.007)$, which is accompanied by a $12.4-$ fold down-regulation of wild-type MLL and MLL-SEPT2 combined expression $(p=0.028)$. The down-regulation of SEPT2 in MLL-SEPT2 myeloid neoplasias was statistically significant when compared with all other leukemia genetic subgroups (including those with other MLL gene fusions). In addition, $M L L$ expression was also down-regulated in the group of MLL fusions other than MLL-SEPT2, when compared with the normal control group $(p=0.023)$

Conclusion: We found a significant down-regulation of both SEPT2 and MLL in MLL-SEPT2 myeloid neoplasias. In addition, we also found that $M L L$ is under-expressed in AML patients with MLL fusions other than MLL-SEPT2. 


\section{Background}

Septins comprise an evolutionarily conserved family of GTP-binding proteins that are found primarily in fungi and animals [1]. In humans, 14 septin genes have been characterized to date (SEPT1 to SEPT14). All septin transcripts contain multiple translation initiation sites and are alternatively spliced, giving origin to multiple septin isoforms, some of which are tissue specific [1]. Although the precise functions of septins remain unclear, current data suggest that they coordinate changes in cytoskeletal and membrane organization by acting as scaffolds that recruit factors to precise sites in a cell and/or as barriers that segregate membrane areas into discrete domains $[1,2]$. For instance, the human SEPT2 associates with SEPT6 and SEPT7 to form an hexamer complex that is the core unit for generation of septin filaments associated with the contractile ring in dividing cells, being therefore essential for proper cytokinesis and chromosome segregation $[2,3]$.

Septins have been reported to be deregulated in various human diseases, including cancer [4]. A relevant role of septins in leukemogenesis has been uncovered by their involvement as fusion partners in MLL-related leukemia. We have established the MLL-SEPT2 gene fusion as the molecular abnormality subjacent to the translocation $\mathrm{t}(2 ; 11)(\mathrm{q} 37 ; \mathrm{q} 23)$ in therapy-related acute myeloid leukemia (t-AML) [5]. Subsequently, van Binsbergen et al [6] identified a second MLL-SEPT2 fusion variant in a patient with t-AML and we have recently uncovered a third MLLSEPT2 alternative fusion variant in a case of therapyrelated myelodysplastic syndrome (t-MDS) $[7,8]$. Four other septin family genes (SEPT5, SEPT6, SEPT9 and SEPT11) had previously been identified as MLL fusion partners in leukemia, making the septins the protein family with more numbers involved in $M L L$-related leukemia [9-13], and suggesting that their involvement in leukemogenesis is not a chance event. This hypothesis is supported by the fact that all the reported $M L L$-septin fusions are in frame and the breakpoints are found at the very 5 ' end of known septin open reading frames [5,9-13]. In this work we show evidence that the fusion of MLL with SEPT2 is associated with down-regulation of both SEPT2 and MLL expression in t-AML/t-MDS.

\section{Methods \\ Patient samples}

We studied 58 acute myeloid leukemia patients (AML) at diagnosis selected to represent the major AML genetic subgroups, including 13 cases with a CBFB-MYH11 rearrangement, 12 cases with a PML-RARA rearrangement, 12 cases with a RUNX1-RUNX1T1 rearrangement, 11 cases with normal karyotype, and 10 cases with rearrangements of the MLL gene other than MLL-SEPT2 [see Additional file 1]. We also studied all three MLL-SEPT2 patients reported in the literature, namely two with t-AML (patients 59 and 60 ) and the third with t-MDS (patient 61), which were the primary targets of our investigation [see Additional file 1] [5-8]. All but patients 60 and 61 were treated at the Portuguese Oncology Institute, Porto, Portugal, and bone marrow samples were obtained to perform cytogenetic and molecular studies. Patients 60 and 61 were treated in the Netherlands at the St. Antonius Hospital, Nieuwegein [6] and the Amsterdam Academic Medical Center [7], respectively, from whom cDNA was obtained.

As a control group we studied bone marrow samples obtained from ten individuals studied for the purpose to rule out a hematological disease.

This study was approved by the Portuguese Oncology Institute ethic committee, and informed consent was obtained from all patients.

\section{Chromosome banding and molecular cytogenetics}

The diagnostic bone marrow samples of the Portuguese patients (cases 1 to 59) were cultured for 24 hours in RPMI 1640 medium with GlutaMAX-I (Invitrogen, London, UK) supplemented with $20 \%$ fetal bovine serum (Invitrogen, London, UK). Chromosome preparations were made by standard methods and banded by trypsinLeishman. Karyotypes were described according to the International System for Human Cytogenetic Nomenclature [14].

Whenever appropriate, fluorescence in situ hybridization (FISH) analysis for specific fusion genes or rearrangements was performed using dual-color, break-apart or dual-fusion, probes (Vysis, Downers Grove, USA).

Chromosome banding and molecular cytogenetic analyses of patients 60 and 61 were described previously $[6,7]$.

\section{RNA extraction and CDNA synthesis}

Total RNA was extracted from the diagnostic bone marrow sample of patients 1 to 59 and controls using $1 \mathrm{ml}$ of Tripure isolation reagent (Roche Diagnostics, Indianapolis, USA) and quantified in a NanoDrop ND-100 spectrophotometer (NanoDrop Technologies, Wilmington, USA). For cDNA synthesis, $1 \mu \mathrm{g}$ of total RNA was subjected to reverse transcription with random hexamers using the Superscript III First-Strand Synthesis System for RT-PCR (Invitrogen, Carlsbad, USA), according to the manufacturer's instructions. The final cDNA was diluted with $30 \mu \mathrm{l}$ of $\mathrm{H}_{2} \mathrm{O}$. cDNA quantity and quality were assessed in a NanoDrop ND-100 spectrophotometer (NanoDrop Technologies, Wilmington, USA).

\section{Qualitative Reverse-Transcription Polymerase Chain Reaction (RT-PCR)}

RT-PCR assays for detection of the fusion transcripts RUNX1-RUNX1T1, CBFB-MYH11, and PML-RARA were performed on the diagnostic samples according to the 
BIOMED-1 protocol [15]. The primers and PCR reaction conditions for the detection of rearrangements involving the $M L L$ gene were previously published $[5,10,16-19]$.

\section{Quantitative Real-Time Polymerase Chain Reaction (qRT- PCR)}

We have evaluated the mRNA expression of MLL and SEPT2 genes by qRT-PCR on an ABI PRISM 7000 Sequence Detection System (Applied Biosystems, Foster City, USA). Primers and probes for MLL and SEPT2 were derived from the published mRNA sequences of SEPT2 and MLL (GenBank accession nos. NM 001008491.1 and NM 005933.2, respectively), and designed with Primer Express 2.0 (Applied BioSystems) and purchased from Metabion (Metabion, Martinsried, Deutschland) [see Additional file 2]. Primers and probes for the ABL1 gene (GenBank accession no. NM 005157), used as endogenous control, were previously described and approved for qRT-PCR based diagnosis and minimal residual disease detection in leukaemic patients, due to be similarly expressed in normal and diagnostic samples as well as within normal samples [see Additional file 2] [20,21]. All primers and probes were designed outside of $M L L$ and SEPT2 breakpoint cluster regions in exons 4-5 and exons $3-4$, respectively. To determine the relative expression levels of the target gene in each sample, the relative amount of the target gene was calibrated to the relative amount of the internal reference gene and expressed in terms of ratios between the target and the reference that were then multiplied by 100 for easier tabulation (target gene/ABL1 $\times 100$ ). PCR reactions were performed in a $25 \mu$ l volume containing $5 \mu \mathrm{l}$ of synthesized cDNA, $12.5 \mu \mathrm{l}$ of TaqMan universal PCR master mix, $0.3 \mu \mathrm{M}$ of each primer and 0.2 $\mu \mathrm{M}$ of each probe. PCR was performed in separate wells for each primer/probe set and each sample was run in triplicate. PCR parameters were as follows: $50^{\circ} \mathrm{C}$ for $2 \mathrm{~min}$., $95^{\circ} \mathrm{C}$ for $10 \mathrm{~min}$., followed by 50 cycles at $95^{\circ} \mathrm{C}$ for $15 \mathrm{~s}$. and $60^{\circ} \mathrm{C}$ for $1 \mathrm{~min}$. Each plate included non-template controls and serial dilutions of a strongly expressing sample (MLL or SEPT2) to construct the standard curves.

\section{Bisulfite treatment}

Sodium bisulfite conversion of unmethylated (but not methylated) cytosine residues to uracil in a sample of genomic DNA obtained from MLL-SEPT2 case 59 (DNA from MLL-SEPT2 cases 60 and 61 was not available) and three normal controls was performed as previously described [22]. Briefly, $500 \mathrm{ng}$ of genomic DNA was denatured with $0.3 \mathrm{M} \mathrm{NaOH}$ in a total volume of $21 \mu \mathrm{l}$ for 20 min. at $50^{\circ} \mathrm{C}$. A volume of $450 \mu \mathrm{l}$ freshly prepared bisulfite solution (2.5 M sodium bisulfite, $125 \mathrm{mM}$ hydroquinone, and $0.2 \mathrm{M} \mathrm{NaOH}$ ) was added to each denaturation reaction, and the mixture was incubated at $70^{\circ} \mathrm{C}$ for 3 hours in the dark. The resulting bisulfite-converted DNA was then purified by using Wizard DNA purification resin
(Wizard DNA Clean-Up System; Promega, Madison, USA) according to the manufacturer's instructions and eluted in $45 \mu \mathrm{l}$ of water preheated at $70^{\circ} \mathrm{C}$. The eluted DNA was denatured in $0.3 \mathrm{M} \mathrm{NaOH}$ for $10 \mathrm{~min}$. at room temperature. Finally, the bisulfite converted and denatured genomic DNA was precipitated with $100 \%$ ethanol, dried, resuspended in $30 \mu \mathrm{l}$ of water, and stored at $-20^{\circ} \mathrm{C}$.

\section{Quantitative Methylation-Specific Polymerase Chain Reaction (qMSP)}

Due to the very low quantity of DNA available from $M L L$ SEPT2 case 59, only the SEPT2 gene could be analyzed by qMSP. The SEPT2 5'-CpG island was identified using the CpG Island Searcher http://cpgislands.com[23] and the SEPT2 genomic sequence (GenBank accession no. NT 005416.12). That CpG island was found to encompass the predicted SEPT2 promoter region using PROSCAN 1.7 [24]. Primers and probe for the SEPT2 5'-CpG island were designed with Methyl Primer Express 1.0 (Applied BioSystems, Foster City, USA), and selected to specifically amplify fully methylated bisulfite-converted DNA [see Additional file 2]. Primers and probe for the internal reference gene, ACTB (GenBank accession no. NM_001101), were described previously [25] and were designed to amplify and detect a region of the gene that is devoid of CpG nucleotides to normalize for DNA input in each sample [see Additional file 2]. qMSP of the chemically modified DNA was performed in an ABI PRISM 7000 Sequence Detection System (Applied Biosystems, Foster City, USA), as previously described [26]. In brief, fluorescence based real-time PCR assays were carried out in a reaction volume of $20 \mu \mathrm{L}$, consisting of $16.6 \mathrm{mM}$ ammonium sulfate, $67 \mathrm{mM}$ trizma preset, $6.7 \mathrm{mM} \mathrm{MgCl}_{2}, 10$ $\mathrm{mM}$ mercaptoethanol, $0.1 \%$ DMSO, $200 \mu \mathrm{M}$ each of dATP, dCTP, dGTP, and dTTP, $600 \mathrm{nM}$ of each primer, 0.4 $\mu \mathrm{L}$ of Rox dye, $200 \mathrm{nM}$ of probe, 1 unit of platinum Taq polymerase (Invitrogen, Carlsbad, USA), and $2 \mu \mathrm{l}$ of bisulfite-modified DNA as a template. PCR was performed in separate wells for each primer/probe set and each sample was run in triplicate. PCR was performed under the following conditions: $95^{\circ} \mathrm{C}$ for $2 \mathrm{~min}$., followed by 45 cycles of $95^{\circ} \mathrm{C}$ for $15 \mathrm{~s}$. and $60^{\circ} \mathrm{C}$ for $1 \mathrm{~min}$.

To ensure the specificity of the analysis, each 96-well PCR plate had wells that contained completely methylated DNA at all CpGs (positive control - CpGenome Universal Methylated DNA, Chemicon Europe, Hampshire, UK), a completely unmethylated DNA (negative control - CpGenome Universal Unmethylated DNA, Chemicon Europe, Hampshire, UK), and multiple water blanks (contamination control). To determine the relative levels of methylated promoter DNA in each sample, we used serial dilutions of the positive control DNA to construct the calibration curve. The values obtained (mean quantity) for each target gene were divided by the respective values of 
the internal reference gene (ACTB). The ratio thus generated, which constitutes an index of the percentage of input copies of DNA that are fully methylated at the primer- and probe-binding sites, was then multiplied by 100 for easier tabulation (methylation level $=$ target gene/reference gene $\times 100)$.

\section{Statistical analyses}

Normalized expression values for MLL and SEPT2 were compared among the different sample groups using the non-parametric Kruskal-Wallis $\mathrm{H}$ and Mann-Whitney U tests. The correlation between MLL and SEPT2 expression values within each group was assessed using Pearson's test. All analyses were performed using SPSS version 15.0 (SPSS, Chicago, USA).

\section{Results}

In all cases, RNA and/or cDNA quantity and quality was evaluated and was found to be appropriate for expression studies. The 260/280 and 260/230 absorbance ratios for RNA samples were in the range of 1.8-2.2. For the cDNA samples, the 260/280 and 260/230 sample absorbance ratios were in the range of $1.6-2.0$ and $1.8-2.2$, respectively.

Normalized expression levels for MLL and SEPT2 within each sample group are depicted in Figure 1. Statistically significant differences were observed for the combined wild-type SEPT2 and MLL-SEPT2 expression in the MLLSEPT2 cases when compared with the normal controls, showing a 12.8-fold lower median expression in the MLLSEPT2 subset $(\mathrm{p}=0.007)$. Furthermore, the combined wild-type SEPT2 and MLL-SEPT2 expression was significantly lower (5.4 to 9.4 fold) in the MLL-SEPT2 cases than in all other leukemia genetic subgroups (Table 1). The combined expression of wild-type MLL and MLL-SEPT2 was also significantly lower $(12.4$ fold; $\mathrm{p}=0.028)$ in the MLL-SEPT2 myeloid neoplasias when compared with the normal controls, as well as with the CBFB-MYH11 and RUNX1-RUNX1T1 leukemia subgroups (13.4 and 10.5 fold, respectively). We next investigated whether DNA hypermethylation of the 5' SEPT2 region was contributing to the SEPT2 gene down-regulation, by examining the methylation status of the CpG island located upstream of the SEPT2 gene transcriptional initiation site [2225 base pair (bp) in length (-7457 to -9257)]. SEPT2 5' CpG island hypermethylation was detected in the positive control, but not in the MLL-SEPT2 case 59 or the normal controls.

No statistically significant differences were observed for the wild-type SEPT2 expression between the non-MLLSEPT2 leukemia subgroups and the normal controls, with the exception of the PML-RARA and "normal karyotype" leukemias that showed lower expression (Table 1). No statistically significant differences were observed for the
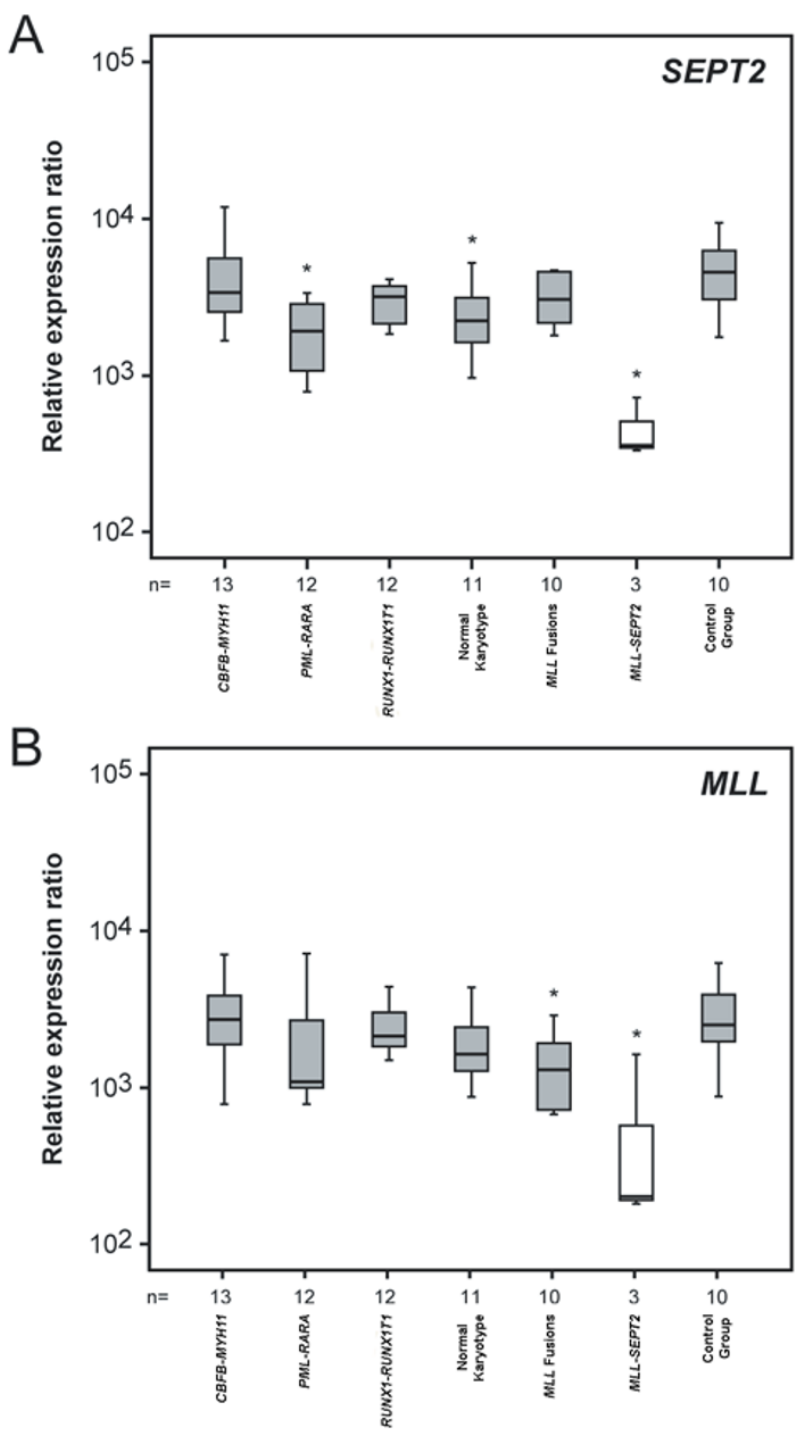

Figure I

Box-plots of normalized expression values for SEPT2 (A) and MLL (B) in subgroups of myeloid malignancies and control samples. Asterisks denote significant differences when compared with the normal control group. The combined expression of MLL-SEPT2 and MLL or SEPT2 was significantly lower in MLL-SEPT2 patients compared to all other groups (see Table I for significance values).

wild-type $M L L$ expression between the non-MLL-SEPT2 leukemia subgroups and the normal controls, with the exception of the significantly lower expression seen in the patient group with $M L L$ fusions with other partners other than SEPT2 $(\mathrm{q}=0,023)$.

\section{Discussion}

Fusion oncogenes are generally thought to contribute to carcinogenesis by either causing over-expression of the $3^{\prime}$ partner due to promoter swap or by originating a chimeric 
Table I: Normalized values for the expression of MLL-SEPT2 and MLL or SEPT2 in subgroups of hematologic malignacies and normal controls

\begin{tabular}{|c|c|c|c|c|c|c|c|c|c|}
\hline \multirow[b]{2}{*}{ Genetic groups } & \multicolumn{3}{|c|}{ SEPT2 + MLL-SEPT2 } & \multicolumn{6}{|c|}{ MLL + MLL-SEPT2 } \\
\hline & $\mathrm{n}$ & $\begin{array}{c}\text { Median } \\
\text { (P25-P75) }\end{array}$ & Fold Change (a) & $P$-value (a) & $P$-value (b) & $\begin{array}{l}\text { Median } \\
(\mathrm{P} 25-\mathrm{P} 75)\end{array}$ & Fold Change (a) & $P$-value (a) & $P$-value (b) \\
\hline CBFB-MYHII & 13 & $\begin{array}{c}3388 \\
(24 I I-5634)\end{array}$ & 9.4 & 0.004 & Ns & $\begin{array}{c}2692 \\
(1698-5099)\end{array}$ & 13.4 & 0.025 & ns \\
\hline PML-RARA & 12 & $\begin{array}{c}1957 \\
(1055-2904)\end{array}$ & 5.4 & 0.004 & 0.001 & $\begin{array}{c}1083 \\
(97 \mid-2698)\end{array}$ & 5.4 & ns & ns \\
\hline RUNXI-RUNXITI & 12 & $\begin{array}{c}3187 \\
(2100-3760)\end{array}$ & 8.9 & 0.004 & ns & $\begin{array}{c}2107 \\
(1765-3018)\end{array}$ & 10.5 & 0.018 & ns \\
\hline Normal Karyotype & 11 & $\begin{array}{c}2242 \\
(1604-3424)\end{array}$ & 6.2 & 0.005 & 0.010 & $\begin{array}{c}1621 \\
(1012-2895)\end{array}$ & 8.1 & ns & ns \\
\hline MLL Fusions & 10 & $\begin{array}{c}3069 \\
(2159-4600)\end{array}$ & 8.5 & 0.007 & ns & $\begin{array}{c}1292 \\
(708-2050)\end{array}$ & 6.4 & ns & 0.023 \\
\hline MLL-SEPT2 & 3 & $\begin{array}{c}359 \\
(333-724)\end{array}$ & 1.0 & - & 0.007 & $\begin{array}{c}200 \\
(180-1612)\end{array}$ & 1.0 & - & 0.028 \\
\hline Normal Control & 10 & $\begin{array}{c}4599 \\
(2939-6365)\end{array}$ & 12.8 & 0.007 & - & $\begin{array}{c}2494 \\
(1749-3929)\end{array}$ & 12.4 & 0.028 & - \\
\hline
\end{tabular}

(a) Comparison of each group with MLL-SEPT2 patients; (b) Comparison of each group with normal control group; (P25) percentile 25; (P75) percentile 75 .

protein with new biochemical properties. Surprisingly, when compared with the normal controls, we found a 12.8-fold reduction of the combined MLL-SEPT2 and wild-type SEPT2 expression in myeloid neoplasias with the MLL-SEPT2 gene fusion, which is accompanied by 12.4-fold down-regulation of the combined MLL-SEPT2 and wild-type MLL expression. The down-regulation of SEPT2 in MLL-SEPT2 myeloid neoplasias was also statistically significant when compared with all other leukemia genetic subgroups (including those with other MLL gene fusions). It is conceivable that deregulation of SEPT2 expression can occur as a result of its fusion with $M L L$ (for example by haplo-insufficiency), since the MLL-SEPT2 gene is under the control of the $M L L$ promoter. However, not only the magnitude of SEPT2 under-expression far exceeds the maximum 50\% reduction that would be expected if one of the SEPT2 gene copies has its expression shutdown, but wild-type $M L L$ expression seems to be strongly down-regulated as well. This suggests a concomitant down-regulation of wild-type $M L L$, wild-type SEPT2, and the MLL-SEPT2 fusion gene. The fact that $M L L$, SEPT2, and MLL-SEPT2 map to distinct chromosomes excludes a localized transcriptional repression affecting contiguous genes via a long-range control element as a possible mechanism.

Interestingly, $M L L$ expression was also down-regulated in the group of $M L L$ fusions other than MLL-SEPT2, when compared with the normal control group. Wild-type $M L L$ down-regulation associated with $M L L$ abnormalities was previously observed in AML with MLL partial tandem duplication (PTD) [27]. In that instance, the wild-type
$M L L$ transcript derived from the non-rearranged $M L L$ allele was absent in the majority of cases of MLL-PTD, with the authors suggesting that the silencing of wild-type $M L L$ may result from the action of the MLL-PTD protein via an auto-regulatory mechanism [27], which has so far not been described for MLL-SEPT2. In addition, downregulation of $M L L$ when fused with a partner gene was also previously observed in MLL-MLLT3 patients [27], suggesting that this can be a common event in $M L L$ related leukemia. Since MLL fusion proteins seem to transform by a gain-of-function mechanism with conversion of the MLL chimera into a potent transcriptional activator $[28,29]$, quantitative oscillations in wild-type and chimeric $M L L$ expression level presumably do not abrogate the leukemogenic properties of $M L L$ fusion proteins. One alternative explanation for the observed down-regulation of MLL, SEPT2 and MLL-SEPT2 is the involvement of a transcriptional rather than post-transcriptional mechanism, for instance regulated via an epigenetic mark. DNA methylation within the promoter region of a gene can result in chromatin compaction and inhibition or downregulation of gene transcription, and aberrant promoter methylation in cis is often responsible for gene silencing in a variety of malignancies [30]. However, the absence of DNA methylation in the CpG island located 5' of the SEPT2 gene (encompassing the predicted SEPT2 promoter region) suggests that hypermethylation of wild-type SEPT2 is probably not the mechanism responsible for the observed gene silencing but, since in only one MLL-SEPT2 case DNA was available to perform methylation analysis, a definitive conclusion cannot be draw. 
How can SEPT2 down-regulation be associated with leukemogenesis? Mammalian septins have been linked with two distinct steps in cell division, namely during chromosome segregation and during cytokinesis, as depletion of septins by siRNA result in defects in both of these processes $[31,32]$. SEPT2 function is dependent of the formation of core oligomeric complexes with SEPT6 and SEPT7, and this septin heterotrimer is a recognized regulator of microtubule stability, with septin depletion resulting in a marked stabilization of microtubules and mitotic defects in vivo $[1,33]$. It is known that proper organization of the cytoskeleton, including that of septin filaments, is required for cell-cycle progression and, as a consequence, septins are indirectly involved in driving or halting the cell-cycle engine [34]. In addition, the SEPT2SEPT6-SEPT7 complex can directly regulate cell-cycle progression by sequestering key signaling molecules involved in the DNA damage response and cell-cycle progression $[33,34]$. Down-regulation of the expression of septin genes has been described previously in neoplasia. Expression of the mitochondrial ARTS protein, a splice variant of the SEPT4 gene, is lost in the majority of childhood acute lymphoblastic leukemias and SEPT9 expression is downregulated by promoter methylation in head and neck squamous cell carcinomas, suggesting that both genes can function as tumor suppressor genes [35,36]. SEPT2 may also play a role in the pathogenesis of other AML subtypes in which it is not involved as fusion partner, since we have uncovered significant SEPT2 RNA down-regulation in AML associated with the PML-RARA rearrangement and in AML with a normal karyotype.

SEPT2 is not the only septin family gene associated with hematological neoplasia. It has been shown that at least four other septins, SEPT5, SEPT6, SEPT9 and SEPT11, are also MLL fusion partners [9-13]. There is increasing evidence supporting the hypothesis that $M L L$ fusion partners are not randomly chosen, but rather functionally selected. For instance, the most frequent MLL fusion partners AFF1 (AF4), MLLT3 (AF9), MLLT1 (ENL) and MLLT10 (AF10) have been shown to belong to the same nuclear protein network [37]. Furthermore, the carboxyl-terminal domain of ELL and MLLT1O have been shown to be required for the leukemic transformation associated with the MLL-ELL and MLL-MLLT10 fusion proteins, respectively $[38,39]$.

\section{Conclusion}

We provide evidence of MLL and SEPT2 down-regulation in MLL-SEPT2 myeloid neoplasia, as well as MLL underexpression in AML with MLL fusions with other partners other than SEPT2 but, due to the small number of MLLSEPT2 cases available, these results should be confirmed in a larger series of patients. Characterization of the expression profile of other MLL fusion partners, including other septins, in hematological malignancies may allow a better understanding of the pathobiological mechanisms of AML.

\section{Competing interests}

The authors declare that they have no competing interests.

\section{Authors' contributions}

NC designed and performed the research, analyzed the data and drafted the manuscript. IS performed the research and analyzed the data. SB performed the RT-PCR studies. VC performed the qMSP studies. FRR analyzed the data. SL, CC, LT, and JV performed the chromosome banding and molecular cytogenetic studies. SS, CHM, and $\mathrm{AB}$ characterized patients 60 and 61 and provide samples of both patients for RT-PCR and qRT-PCR studies. JMM and LN clinically assessed the patients. MRT coordinated the study and participated in manuscript writing. All authors read and approved the final manuscript.

\section{Additional material}

\author{
Additional file 1 \\ Additional Table S1. Summary of clinical, molecular, and cytogenetic \\ data of the 61 patients with hematological malignacies. \\ Click here for file \\ [http://www.biomedcentral.com/content/supplementary/1471- \\ 2407-9-147-S1.doc]

\section{Additional file 2} \\ Additional Table S2. Oligonucleotide primers and probes (5'FAM, \\ 3 'TAMRA) used in this study. \\ Click here for file \\ [http://www.biomedcentral.com/content/supplementary/1471- \\ 2407-9-147-S2.doc]
}

\section{Acknowledgements}

This research was supported by grants from the "Associação Portuguesa Contra a Leucemia" (2006-30.2.AP/MJ) and the "Comissão de Fomento da Investigação em Cuidados de Saúde" (P.I. 26/2007).

\section{References}

I. Weirich CS, Erzberger JP, Barral Y: The septin family of GTPases: architecture and dynamics. Nat Rev Mol Cell Biol 2008, 9:478-489.

2. Gladfelter AS, Montagna C: Seeking truth on Monte Verita. Workshop on the molecular biology and biochemistry of septins and septin function. EMBO Rep 2007, 8: I I 20- I I 26.

3. Joo E, Surka MC, Trimble WS: Mammalian SEPT2 is required for scaffolding nonmuscle myosin II and its kinases. Dev Cell 2007, 13:677-690.

4. Hall PA, Russell SE: The pathobiology of the septin gene family. J Pathol 2004, 204:489-505.

5. Cerveira N, Correia C. Bizarro S, Pinto C, Lisboa S, Mariz JM, Marques M, Teixeira MR: SEPT2 is a new fusion partner of MLL in acute myeloid leukemia with $t(2 ; 11)(q 37 ; q 23)$. Oncogene 2006, 25:6|47-6I52.

6. van Binsbergen $E$, de Weerdt $O$, Buijs A: A new subtype of $M L L-$ SEPT2 fusion transcript in therapy-related acute myeloid leukemia with $t(2 ; 11)(q 37 ; q 23)$ : a case report and literature review. Cancer Genet Cytogenet 2007, 1 76:72-75. 
7. Snijder $\mathrm{S}$, Mellink $\mathrm{CH}$, Lelie $\mathrm{H}$ van der: Translocation $(2 ; I I)(q 37 ; q 23)$ in therapy-related myelodysplastic syndrome after treatment for acute promyelocytic leukemia. Cancer Genet Cytogenet 2008, I 80:|49-I52.

8. Cerveira N, Santos J, Pinheiro M, Snijder S, Lelie H van der, Mellink C, Teixeira MR: A novel MLL-SEPT2 fusion variant in therapyrelated myelodysplastic syndrome. Cancer Genet Cytogenet 2008, I 85:62-64.

9. Megonigal MD, Rappaport EF, Jones DH, Williams TM, Lovett BD, Kelly KM, Lerou PH, Moulton T, Budarf ML, Felix CA $t(I$ I;22)(q23;q I I.2) in acute myeloid leukemia of infant twins fuses MLL with hCDCrel, a cell division cycle gene in the genomic region of deletion in DiGeorge and velocardiofacial syndromes. Proc Natl Acad Sci USA 1998, 95:64I 3-64I8.

10. Osaka M, Rowley JD, Zeleznik-Le NJ: MSF (MLL septin-like fusion), a fusion partner gene of $M L L$, in a therapy-related acute myeloid leukemia with a t(I I; I7)(q23;q25). Proc Natl Acad Sci USA 1999, 96:6428-6433.

II. Taki T, Ohnishi H, Shinohara K, Sako M, Bessho F, Yanagisawa M, Hayashi Y: AFI7q25, a putative septin family gene, fuses the MLL gene in acute myeloid leukemia with $\mathrm{t}(\mathrm{I} 1 ; \mathbf{I} 7)(\mathrm{q} 23 ; \mathrm{q} 25)$. Cancer Res 1999, 59:426I-4265.

12. Ono R, Taki T, Taketani T, Kawaguchi H, Taniwaki M, Okamura T, Kawa K, Hanada R, Kobayashi M, Hayashi Y: SEPTIN6, a human homologue to mouse Septin6, is fused to $M L L$ in infant acute myeloid leukemia with complex chromosomal abnormalities involving I I q23 and Xq24. Cancer Res 2002, 62:333-337.

13. Kojima K, Sakai I, Hasegawa A, Niiya H, Azuma T, Matsuo Y, Fujii N, Tanimoto M, Fujita S: FLJ $\mathbf{0 8 4 9}$, a septin family gene, fuses $M L L$ in a novel leukemia cell line CNLBCI derived from chronic neutrophilic leukemia in transformation with t(4; I I)(q2 I;q23). Leukemia 2004, I 8:998-I005.

14. Shaffer LG, Tommerup N: ISCN 2005 An International System for Human Cytogenetic Nomenclature Basel: Karger; 1995.

15. van Dongen JJ, Macintyre EA, Gabert JA, Delabesse E, Rossi V, Saglio G, Gottardi E, Rambaldi A, Dotti G, Griesinger F, Parreira A, Gameiro P, Diaz MG, Malec M, Langerak AW, San Miguel JF, Biondi A: Standardized RT-PCR analysis of fusion gene transcripts from chromosome aberrations in acute leukemia for detection of minimal residual disease. Report of the BIOMED-I Concerted Action: investigation of minimal residual disease in acute leukemia. Leukemia 1999, I 3:1901-1928.

16. Chaplin T, Bernard O, Beverloo HB, Saha V, Hagemeijer A, Berger R, Young BD: The $t(10 ; \mid I)$ translocation in acute myeloid leukemia (M5) consistently fuses the leucine zipper motif of AFIO onto the HRX gene. Blood 1995, 86:2073-2076.

17. Poirel H, Rack K, Delabesse E, Radford-Weiss I, Troussard X, Debert C, Leboeuf D, Bastard C, Picard F, Veil-Buzyn A, Flandrin G, Bernard $\mathrm{O}$, Macintyre $\mathrm{E}$ : Incidence and characterization of $M L L$ gene ( I q23) rearrangements in acute myeloid leukemia $M I$ and M5. Blood 1996, 87:2496-2505.

18. Busson-Le Coniat M, Salomon-Nguyen F, Hillion J, Bernard OA, Berger R: MLL-AFIq fusion resulting from $t(I ; I I)$ in acute leukemia. Leukemia 1999, 13:302-306.

19. Shih LY, Liang DC, Fu JF, Wu JH, Wang PN, Lin TL, Dunn P, Kuo MC, Tang TC, Lin TH, Lai CL: Characterization of fusion partner genes in I I4 patients with de novo acute myeloid leukemia and MLL rearrangement. Leukemia 2006, 20:218-223.

20. Gabert J, Beillard E, Velden VH van der, Bi W, Grimwade D, Pallisgaard N, Barbany G, Cazzaniga G, Cayuela JM, Cavé H, Pane F, Aerts JL, De Micheli D, Thirion X, Pradel V, González M, Viehmann S, Malec M, Saglio G, van Dongen J]: Standardization and quality control studies of 'real-time' quantitative reverse transcriptase polymerase chain reaction of fusion gene transcripts for residual disease detection in leukemia - a Europe Against Cancer program. Leukemia 2003, I7:23 I8-2357.

21. Beillard E, Pallisgaard N, Velden VH van der, Bi W, Dee R, Schoot E van der, Delabesse E, Macintyre E, Gottardi E, Saglio G, Watzinger F, Lion T, van Dongen J], Hokland P, Gabert J: Evaluation of candidate control genes for diagnosis and residual disease detection in leukemic patients using 'real-time' quantitative reverse-transcriptase polymerase chain reaction (RQ-PCR) - a Europe against cancer program. Leukemia 2003, | 7:2474-2486
22. Clark SJ, Harrison J, Paul CL, Frommer M: High sensitivity mapping of methylated cytosines. Nucleic Acids Res 1994, 22:2990-2997.

23. Takai D, Jones PA: The CpG island searcher. In Silico Biology 2003, 3:2I.

24. Prestridge DS: Predicting Pol II promoter sequences using transcription factor binding sites. I Mol Biol I995, 249:923-932.

25. Eads CA, Danenberg KD, Kawakami K, Saltz LB, Blake C, Shibata D, Danenberg PV, Laird PW: MethyLight: a high-throughput assay to measure DNA methylation. Nucleic Acids Res 2000, 28:E32.

26. Eads CA, Lord RV, Wickramasinghe K, Long TI, Kurumboor Sk, Bernstein L, Peters JH, DeMeester SR, DeMeester TR, Skinner KA, Laird PW: Epigenetic patterns in the progression of esophageal adenocarcinoma. Cancer Res 2001, 61:3410-3418.

27. Whitmann SP, Liu S, Vukosavljevic T, Rush LJ, Liu C, Klisovic MI, Maharry K, Guimond M, Strout MP, Becknell B, Dorrance A, Klisovic RB, Plass C, Bloomfield CD, Marcucci G, Caligiuri MA: The MLL partial tandem duplication: evidence for recessive gain-offunction in acute myeloid leukemia identifies a novel patient subgroup for molecular-targeted therapy. Blood 2005, 106:345-352.

28. Schreiner SA, García-Cuéllar MP, Fey GH, Slany RK: The leukemogenic fusion of MLL with ENL creates a novel transcriptional transactivator. Leukemia 1999, I3:I525-I533.

29. Zeisig BB, Schreiner S, García-Cuéllar MP, Slany RK: Transcriptional activation is a key function encoded by MLL fusion partners. Leukemia 2003, I 7:359-365.

30. Esteller $M$ : Epigenetics in cancer. $N$ Engl J Med 2008, 358: I |48-II59.

31. Kinoshita M, Kumar S, Mizoguchi A, Ide C, Kinoshita A, Haraguchi T, Hiraoka $Y$, Noda M: Nedd5, a mammalian septin, is a novel cytoskeletal component interacting with actin-based structures. Genes Dev 1997, I I:I535-1547.

32. Spiliotis ET, Kinoshita M, Nelson WJ: A mitotic septin scaffold required for Mammalian chromosome congression and segregation. Science 2005, 307: I78I-1785.

33. Kremer BE, Haystead T, Macara IG: Mammalian septins regulate microtubule stability through interaction with the microtubule-binding protein MAP4. Mol Biol Cell 2005, I 6:4648-4659.

34. Kremer BE, Haystead T, Macara IG: Septins regulate actin organization and cell-cycle arrest through nuclear accumulation of NCK mediated by SOCS7. Cell 2007, I30:777-779.

35. Elhasid R, Sahar D, Merling A, Zivony $Y$, Rotem A, Ben-Arush M, Izraeli S, Bercovich D, Larisch S: Mitochondrial pro-apoptotic ARTS protein is lost in the majority of acute lymphoblastic leukemia patients. Oncogene 2004, 23:5468-5475.

36. Bennett KL, Karpenko M, Lin MT, Claus R, Arab K, Dyckhoff G, Plinkert P, Herpel E, Smiraglia D, Plass C: Frequently methylated tumor suppressor genes in head and neck squamous cell carcinoma. Cancer Res 2008, 68:4494-4499.

37. Meyer C, Schneider B, Jakob S, Strehl S, Attarbaschi A, Schnittger S, Schoch C, Jansen MWJC, van Dongen JJM, den Boer ML, Pieters R, Ennas M-G, Angelucci E, Koehl U, Greil ], Griesinger F, zur Stadt U, Eckert C, Szczepañski T, Niggli FK, Schäfer BW, Kempski H, Brady HJM, Zuna J, Trka J, Nigro LL, Biondi A, Delabesse E, Macintyre E, Stanulla M, Schrappe M, Haas OA, Burmeister T, Dingermann T, Klingebiel T, Marschalek R: The $M L L$ recombinome of acute leukemias. Leukemia 2006, 20:777-784.

38. DiMartino JF, Miller T, Ayton PM, Landewe T, Hess JL, Clearly ML, Shilatifard A: A carboxy-terminal domain of ELL is required and sufficient for immortalization of myeloid progenitors by MLL-ELL. Blood 2000, 96:3887-3893.

39. DiMartino JF, Ayton PM, Chen EH, Naftzger CC, Young BD, Clearly ML: The AF I 0 leucine zipper is required for leukemic transformation of myeloid progenitors by MLL-AF I 0. Blood 2002 , 99:3780-3785.

\section{Pre-publication history}

The pre-publication history for this paper can be accessed here:

http://www.biomedcentral.com/1471-2407/9/147/pre pub 